\title{
Bilateral Supernumerary Sternocleidomastoid Heads with Critical Narrowing of the Minor and Major Supraclavicular Fossae: Clinical and Surgical Implications
}

\author{
Cabezas Supernumerarias Bilaterales del Músculo Esternocleidomastoídeo con Estrechamiento Crítico \\ de las Fosas Supraclavicular Menor y Mayor: Implicancias Clínicas y Quirúrgicas
}

\author{
${ }^{*, * *, * * *, * * * *}$ Athanasios Raikos; ${ }^{* * * *}$ George K. Paraskevas; ${ }^{* * * *}$ Stefanos Triaridis; \\ ${ }^{* * *}$ Panagiota Kordali; ${ }^{* * * *}$ George Psillas \& ${ }^{* *}$ Beate Brand-Saberi
}

\begin{abstract}
RAIKOS, A.; PARASKEVAS, G. K.; TRIARIDIS, S.; KORDALI, P.; PSILLAS, G. \& BRAND-SABERI, B. Bilateral supernumerary sternocleidomastoid heads with critical narrowing of the minor and major supraclavicular fossae: clinical and surgical implications. Int. J. Morphol., 30(3):927-933, 2012.
\end{abstract}

SUMMARY: Anatomical variations of the sternocleidomastoid muscle are rare and concern its origin, insertion, and the number of heads. We report on a rare bilateral variant of the sternocleidomastoid muscle with aberrant and supernumerary muscular heads, observed in a cadaveric subject. On the right side of the neck, a typical sternomastoid head of the sternocleidomastoid muscle, and three aberrant clavicular heads of variable thickness, origin, and termination were noticed. On the left side, two sternomastoid heads were present; the medial one was of typical pattern, while the lateral was supernumerary. The cleidomastoid portion of the left sternocleidomastoid muscle was fused with the double sternomastoid segment. A strap-like muscle originating from the middle third of the clavicle and inserting onto the transverse process of the $\mathrm{C} 3$ vertebra was noticed. This is known as the cleidocervical muscle. On the right side of the neck, the posterior cervical triangle was diminished, the minor supraclavicular fossa was considerably narrow, whereas on the left, it was diminished in addition to a bilateral shortening of the major supraclavicular fossa minimizing space needed for potential surgical access. These findings are of prominent significance for anesthetists in ultrasound guided needle positioning in brachial plexus block, as well as in subclavian or external jugular vein catheterization, and in surgical interventions involving structures lying under the sternocleidomastoid muscle.

KEY WORDS: Cleidocervical; Cleido-occipital; Sternocleidomastoid; Sternomastoid; Supraclavicular fossa; Ultrasound; Variant.

\section{INTRODUCTION}

The sternocleidomastoid muscle (SCM) has been acknowledged from surgeons of the head and neck as a significant anatomical landmark of the anterior and lateral neck region while carries prominent interest for anesthetists. Equitably, it can be called as the "Pandora's box" (Hasan, 2011), as it provides coverage to many important deeper lying structures such as the accessory nerve, brachial plexus, cervical plexus nerves, carotid artery, jugular vein, and jugular chain lymph nodes. The anterior and posterior rim of the SCM serves as the boundary for the division of each hemineck into the anterior and posterior cervical triangle respectively, whilst its two heads near their origin create the minor supraclavicular fossa. The SCM can be subdivided into superficial and deep parts, while the amount of fusion between the two SCM heads varies considerably between subjects (Bergman et al., 1988). The cleidomastoid segment of the SCM can be found as an independent muscle belly in $10 \%$ of cases (Mori, 1964). The anatomical variability is attributed to differences in the arrangement of the layers and parts of the SCM. A summary of the typical and aberrant SCM features are presented in Table I.

We describe a rare variation of combining bilateral aberrant SCM anatomy which is of anatomical interest but also considerable surgical and clinical importance during neck dissections, excision of the deep cervical lymph nodes, carotid artery surgery, venous or arterial catheterization, and in ultrasound guided brachial plexus block techniques. A concise review of the relevant literature is also provided.

* Department of Anatomy, Faculty of Health Sciences \& Medicine, Bond University, Gold Coast, Australia.

** Department of Anatomy \& Molecular Embryology, Medical Faculty, Ruhr University, Bochum, Germany.

*** Department of Anatomy, Medical School, Aristotle University of Thessaloniki, Greece.

***** Department of Otorhinolaryngology, Head \& Neck Surgery, AHEPA University Hospital, Thessaloniki, Greece. 
RAIKOS, A.; PARASKeVAS, G. K.; TRIARIDIS, S.; KORDALI, P.; PSILLAS, G. \& BRAND-SABERI, B. Bilateral supernumerary sternocleidomastoid heads with critical narrowing of the minor and major supraclavicular fossae: clinical and surgical implications. Int. J. Morphol., 30(3):927-933, 2012.

Table I. Resume of typical and aberrant anatomy of the sternocleidomastoid muscle modulated by supernumerary muscular heads.

2 Heads: Sternal (round) sternomastoid, Clavicular (fl attened) sterno-occipital.

Typical features of the sternocleidomastoid muscle

Types of possible variants

\section{External macroscopic findings}

Differential diagnosis

Clinical and surgical significance
2 Layers: Superficial, Deep.

5 Parts: Superficial: superficial sternomastoid, sterno-occipital, cleido-occipital. Deep: sternomastoid, cleidomastoid.

Terminologia Anatomica reference number: A04.2.01.008.

Supernumerary muscular head, absence of muscular head, complete absence, hypoplastic head, supernumerary head with non-typical origin and/or insertion, fusion with trapezius or neighboring muscles or structures.

Usually none.

Hard muscular bulb or mass.

From: cyst, heman gioma, hematoma, glomus tumor, neurofibroma, tumor, lymphadenopathy, thrombosed vein, other muscles in the region.

Mild to severe narrowing of the minor and major supraclavicular fossa, misinterpretation with other muscle or vessel.

\section{CASE REPORT}

During routine dissection of a Caucasian 76-yearsold formalin-fixed female cadaver, an aberrant anatomy was noticed after removal of the superficial cervical fascia along with the platysma muscle in the lateral neck region. On the right side, instead of a normal SCM, four muscle bellies were recorded, in terms of heads one sternal and three clavicular (Fig. 1). The medial of the four heads had anatomy corresponding to the usual sternomastoid portion of the SCM. It was extended from the sternal manubrium to the mastoid process tip. The second head was a narrow strap-like muscle extending from the sternoclavicular joint, posterior and lateral to the origin of the sternomastoid muscle, and conjoined with the third head at the level of crossing with the omohyoid muscle. The third muscle head originated with a double tendinous insertion from the lateral part of the proximal third of the clavicle and terminated at the occipital bone just inferior to the insertion of the sternomastoid head. This anatomical pattern is termed as a cleido-occipital muscle. A fourth muscle head, arose from the middle third of the clavicle, coursed upwards, posteriorly, and obliquely, in a parallel course to the previously described muscle bellies and fused onto the cleido-occipital muscle at the level of the middle third of the anterior border of the trapezoid muscle. This muscle can be considered as a supernumerary cleido-occipital or as a double cleido-occipital muscle. The non-typical arrangement of the muscle tendons on the right side of the neck created a very narrow minor supraclavicular fossa medially. Laterally, an even narrower additional minor supraclavicular fossa laterally and posterior cervical triangle was found, while the major supraclavicular fossa was shortened considerably.
On the left side of the neck, a non-typical muscular pattern of the SCM was also observed (Fig. 2). A supernumerary sternomastoid head arose from sternoclavicular joint just laterally to the tendinous origin of the normal sternomastoid head. The two muscle bellies coursed in parallel arrangement and fused together at the level of the posterior border of the omohyoid muscle, and terminated at the mastoid process. Deeper and laterally to the complex of the sternomastoid heads, the cleidomastoid segment of the SCM was identified. It fused with the double sternomastoid at the level of the posterior border of the omohyoid muscle. Additionally, a strap-like muscle originating from the middle third of the clavicle was noticed. It coursed superiorly and caudally, lying under the complex of the SCM and inserted onto the transverse process of the C3 vertebra. According to its pattern, it was the known as cleidocervical muscle.

Interestingly, a variant of the anterior jugular vein was encountered bilaterally (Fig. 3). The vein branched off from the retromandibular vein on each side of the neck, and had an oblique/medial course on each anterior cervical triangle. The two veins confluence, at the level of the thyroid gland isthmus, forming a high positioned jugular venous arch which emptied via a solitary vein branch into the left external jugular vein. The jugular venous arch was found at least $5 \mathrm{~cm}$ higher than its expected position.

The muscular variants presented in the current study were not identifiable by naked eye or palpation prior to dissection, whereas the rest of the muscles in the neck had typical anatomy. All the normal and aberrant muscles found were covered by the investing layer of the deep cervical fascia, and were innervated mainly by the accessory nerve 


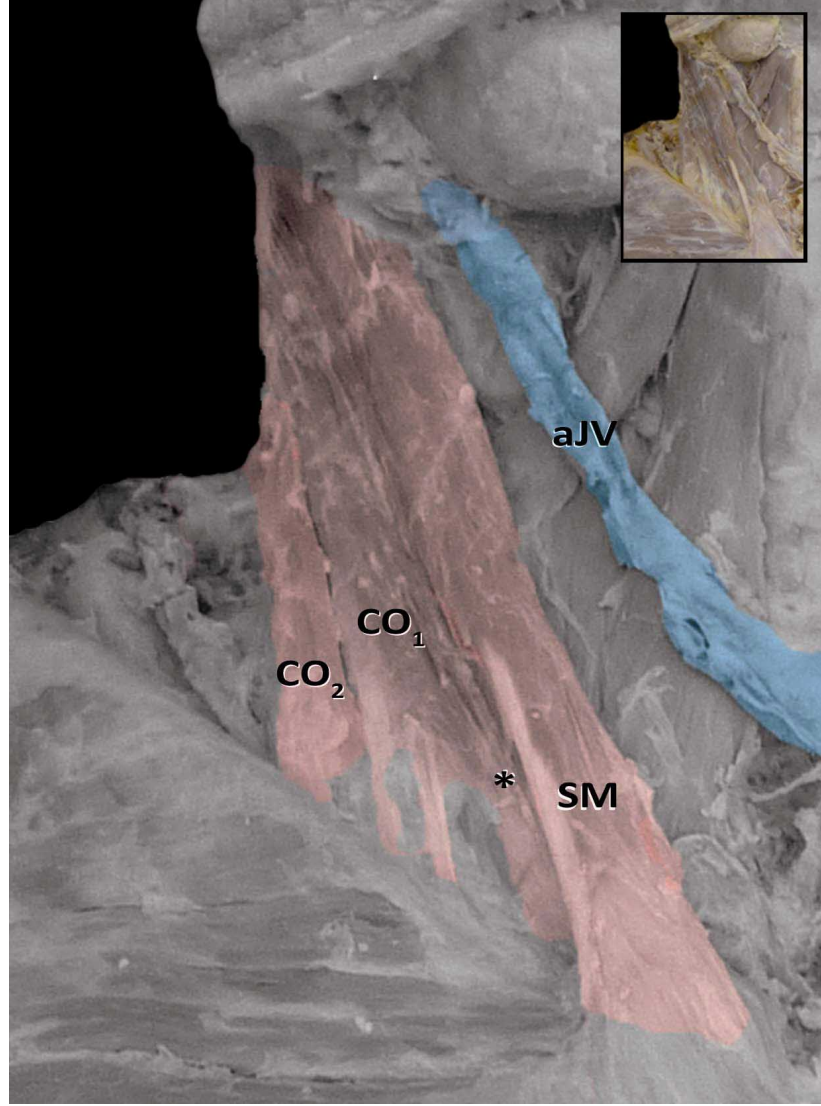

Fig. 1. Multiple aberrant muscular anatomy (highlighted in rose) of the right anterior and lateral neck region involving the sternocleidomastoid muscle. Notice the muscular bundle (*) originating from the sternoclavicular joint and fused with the laterally situated cleido-occipital muscle (CO1) at the level of the lower half of the omohyoid muscle. (SM: sternomastoid segment of the sternocleidomastoid muscle, $\mathrm{CO} 2$ : A second cleido-occipital muscle lied laterally, aJV: anterior jugular vein highlighted in blue).

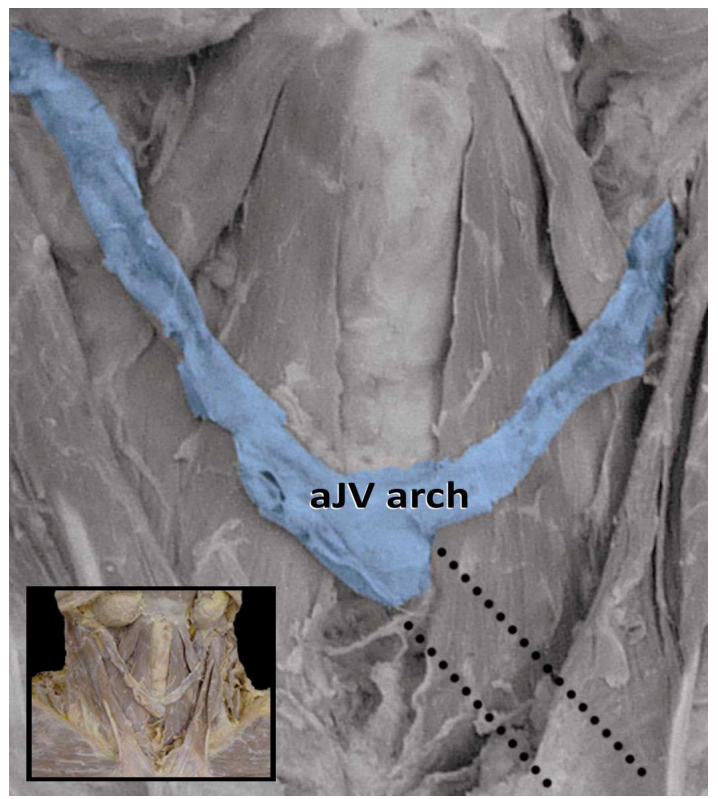

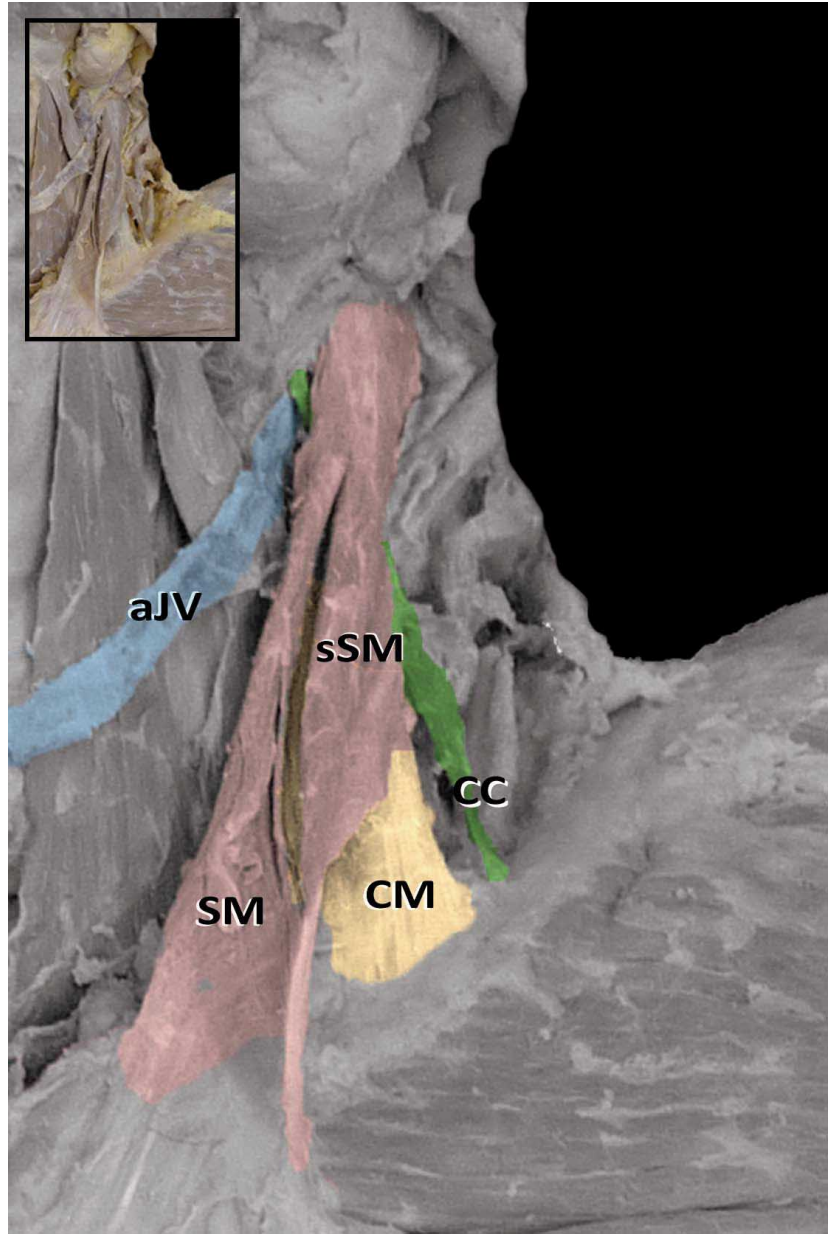

Fig. 2. Duplicated sternocleidomastoid segment of the sternocleidomastoid muscle (highlighted in rose) fused with the cleidomastoid portion of the sternocleidomastoid (highlighted in yellow) at the level of the posterior border of the omohyoid muscle. A cleido-cervical muscle (CC, highlighted in green) was found just posterior to the supernumerary sternomastoid muscle (sSM). (SM: ordinary sternomastoid portion united with a supernumerary sternomastoid muscle, aJV: anterior jugular vein highlighted in blue).

Fig. 3. The right and left anterior jugular veins confluence and form an arch at the level of the thyroid isthmus (aJV arch, highlighted in blue). The dotted lines correspond to the continuity of the vein which emptied on the left external jugular vein, prior to dissection and resection. and by a few branches of the transverse cervical nerve. The subject's medical history did not contain any information regarding neck or laryngeal pathology, or previous neck interventions. From the inspection of the neck, we concluded that the minor supraclavicular fossa was extensively narrowed on the right and disappeared on the left side of the neck due to the presence of the densely arranged supernumerary muscle heads. Additionally, on the right side of the neck, the major supraclavicular fossa was significantly diminished at its medial segment. 
RAIKOS, A.; PARASKEVAS, G. K.; TRIARIDIS, S.; KORDALI, P.; PSILLAS, G. \& BRAND-SABERI, B. Bilateral supernumerary sternocleidomastoid heads with critical narrowing of the minor and major supraclavicular fossae: clinical and surgical implications. Int. J. Morphol., 30(3):927-933, 2012.

Table II. Terminology of typical and aberrant sternocleidomastoid muscles.

$\begin{array}{ll}\text { Typical stemocleidomastoid } & \begin{array}{l}\text { Sternocleidomastoid, Sternomastoid, Sternocleidomastoideus, Musculus } \\ \text { mastoideus colli, Musculus nutator capitis, Muscle of Kopfnicker, }\end{array} \\ \text { Synonyms } & \begin{array}{l}\text { Sternocleidomastoid variants and synonyms } \\ \text { Origin: From clavide to } \\ \text { skull base }\end{array} \\ \begin{array}{l}\text { Origin: From clavide to } \\ \text { vertebra }\end{array} & \begin{array}{l}\text { Cleido-occipital, Cleido-occipitalis, Cleido-occipitalis cervicalis, Sternocleido- } \\ \text { occipital, Cleido-occipital platysma, sternocleido-occipital. } \\ \text { Claviculae, cleidoepistrophicus, cleidotransversarius, cleidotrachélien, } \\ \text { omocervicalis, omotrachelien, trachelo-acromial. }\end{array}\end{array}$

\section{DISCUSSION}

A wide variety of anatomical variants of the SCM has been reported in the literature so far, while their terminology derives from the origin and insertion (Table II). The SCM can be occasionally separated into several muscular strips situated in close relation to each other and their margins can be separated by variably sized gaps.

The cleidocervical muscle usually originates from the clavicle or the acromion and inserts to one or more of the transverse processes of the cervical vertebrae. Its frequency is estimated to be 1-3\% (Fasel et al., 1994), but probably it is even lower as judged by the very few reports in the literature (Tomo et al., 1994). When the muscle terminates on the transverse process of the atlas it is termed as cleidoatlanticus muscle, which is a very rare variant with only four reports in the literature (Grüber, 1876; Koshy et al., 2005; Rodríguez-Vázquez et al., 2009; Feigl \& Pixner, 2011). However, it may be difficult to distinguish if an observed tendon is inserted or emerges from a given structure in the cadaver accounting for problems in the determination of cleidoatlanticus and levator claviculae muscle, which macroscopically may look very similar but has a contrariwise function. The incidence of levator claviculae muscle is reported to range from $0.1-2.97 \%$ (Loukas et al., 2008; Rubinstein et al., 1999; Wood, 1869), and to be more frequent on the left side according to a study on CT scans (Rubinstein et al.). The complete absence of the SCM is very rare and can be presented with an asymmetrical neck contour (Vajramani et al., 2010). It has been reported to be associated with paradoxical movement of the soft tissues in the supraclavicular fossa in a neonate (Haroon \& Beverley, 2004), reduced lateral neck flexion (Vajramani et al.), and lung herniation (Bayne et al., 1997). According to the standard anatomical literature, the posterior fibers of the clavicular head of a typical SCM are usually inserted onto the superior nuchal line and to the occipital bone forming a continuous muscle sheet with the rest segments of the SCM (Last, 1978). The muscle sheet is termed as cleido-occipital, and needs to be distinguished from the real cleido-occipital muscle which is a supernumerary/aberrant head of the SCM originating from the clavicle and attached into the occipital bone as described in the current report. The cleido-occipital element of the SCM had been reported to fuse with the trapezius muscle (Kwak et al., 2003). The reported incidence of the cleidooccipital muscle ranges from $4.16 \%$ to $36.3 \%$ (Sarikcioglu et al., 2001; Wood, 1869). The muscle can be also found bilaterally (Rahman \& Yamadori, 1994).

The SCM shares a common developmental origin with trapezius muscle. The muscle develops from the occipital lateral plate mesoderm, and there is no segmented somatic material responsible for it (Theis et al., 2010). We consider that the variety of SCM origins, terminations, and blending to adjacent muscles and structures, strengthens this opinion. The cleidocervical muscle appears regularly in apes and other mammals but rare in humans (Le Double, 1897; Aiello \& Dean, 1990). It has been proposed that the axis of the cleidocervical muscle determines its embryological origin from the primordia of the ventrolateral neck muscles, similarly to the scalene muscles and the infrahyoid muscles (Wood), while others propose that it develops from the primordia of the occipital neck muscles, such as the SCM or trapezius muscle (Wood; Parsons 1898). A more recent observation, assumes that the cleidocervical muscle appears due to an atavistic effect through a migration mechanism of the most superficial and cranial cells towards the clavicle (Leon et al., 1995). There are a few reports in the literature of a bilateral additional third SCM head (Nayak et al., 2006), while publications commenting on bilateral multiple supernumerary SCM heads are very limited (Natsis et al., 2009; Ramesh et al., 2007). It seems that the origin of the SCM heads is similar between the reported cases but their termination shows a great variability. 
Precise knowledge of the possible muscular variations that can be encountered in the neck region, are very valuable for the anesthetist during regional anesthesia and the subclavian artery and vein catheterization (Natsis et al., 2009). Additionally, may aid the surgeons intervening in the anterior and lateral neck region in order to avoid unwarranted manipulations and possible damage to cardinal structures. Aberrant or supernumerary muscles of the neck could be observed as soft-tissue shadows in modern CT and MR imaging. Three-dimensional reconstruction of the soft tissues and muscles in the suspicious area could assist in avoidance of any differential diagnosis pitfalls (Fasel et al.). A similar supernumerary muscular bundle, such as the one lying adjacent to the sternomastoid portion of the SCM on the right side in the current study has been reported previously by Coskun et al. (2002). The aberrant SCM anatomy could mimic pathological masses of the lateral neck region on clinical and imaging studies including metastatic disease, or benign tumors such as cyst, glomus tumor, neurofibroma, thrombosed vein, hematoma, familiar sternocleidomastoid tumor of infancy, and hypertrophy of the SCM (Rudisuli, 1995; Ruiz Santiago et al., 2001; Rubinstein et al.; Tavill \& Wetmore, 1996; Fasel et al.).

It should be emphasized that the minor supraclavicular fossae of our report were not featured by the typical triangular pattern and were filled with considerably less fibrofatty tissue than expected. This fact could lead to potential problems in interscalene brachial plexus block, subclavian, external, and internal jugular vein catheterization. Ultrasound guidance may reveal anatomical variations of importance for performing brachial plexus blocks and should be preferred over classic blind methods such as nerve stimulation (Klaastad et al., 2009). If the needle is misplaced this could result in poor preoperative anesthesia or postoperative analgesia, risk of nerve injury, hemorrhage, local anesthetic toxicity from increased dosage administration, or pneumothorax (Feigl \& Pixner; Klaastad et al.). It should be stressed, that the cleidocervical muscle recorded on the left side of our subject, lied anterior to the middle scalene muscle and posterior to the double sternomastoid muscle. This relation could potentially mislead the ultrasonographer to misinterpret the muscle as the middle scalene muscle thus leading to insufficient brachial plexus block. The multiple variants of the SCM described in this study are expected to have an additional functional contribution during the elevation of the clavicle or rotation and flexion of the head.

The segments of the SCM may be utilized as a muscle or myocutaneous flap for the reconstruction of regional softtissue defects after traumatic and oncologic head \& neck procedures, thus rehabilitation of oral cavity defects, reanimation of the face, aiding in shoulder elevation, added protection to the carotid and innominate arteries. The preserved segments of the SCM prevent the possibility of significant drooping and limitation in shoulder-joint movements (Conley \& Gullane, 1980). Interestingly, in a patient treated with botulinum toxin for irradiation induced cervical muscle spasm, pain relief was achieved only after an increased dosage administration due to anatomical variation of the SCM (Van Daele et al., 2002). The presence of aberrant or supernumerary muscles in the lateral neck region can limit the access and make difficult the dissection of level IV and V cervical lymph nodes and neurovascular elements during a variety of surgical procedures. Furthermore, the segments of the SCM can serve as anatomical landmarks in localization of the minor and major supraclavicular fossa for the effective cannulation of the internal jugular vein (Asouhidou et al., 2008). In our subject, the accurate identification of the posterior margin of the SCM to serve as a topographic landmark is misleading if an ultrasonographic identification is the case. As described in the case report section, the anterior jugular veins of our subject had an unusual anatomy. The combination of a high positioned jugular venous arch and the solitary communication of the anterior jugular vein into the left external jugular vein may have potential implications in venous catheter placement if the anterior jugular vein was chosen.

The multiple bilateral muscular variations presented in this study are rare and their combination in the same subject comprises a unique case with significant surgical, radiological, and anesthesiologic interest. In addition, the supernumerary muscles, if their presence is identified, could serve as an excellent candidate for myocutaneous flap for the reconstruction of deficits after parotidectomy, oral cavity tumor resection, and esophagoplasty (Asal et al., 2005; Tanaka et al., 2003).

RAIKOS, A.; PARASKEVAS, G. K.; TRIARIDIS, S.; KORDALI, P.; PSILLAS, G. \& BRAND-SABERI, B. Cabezas supernumerarias bilaterales del músculo esternocleidomastoídeo con estrechamiento crítico de las fosas supraclavicular menor y mayor: Implicancias clínicas y quirúrgicas. Int. J. Morphol., 30(3):927-933, 2012.

RESUMEN: Las variaciones anatómicas del músculo esternocleidomastoideo son poco frecuentes y se refieren a su origen, inserción, y número de cabezas. Se presenta una rara variante del músculo esternocleidomastoideo con cabezas musculares aberrantes y supernumerarias bilateralmente en un cadáver. En el lado derecho del cuello, se observaron la cabeza esternomastoidea típica del músculo esternocleidomastoideo, y tres cabezas claviculares aberrantes de origen, espesor y terminación variable. En el lado izquierdo, se observaron dos cabezas esternomastoídeas, 
RAIKOS, A.; PARASKEVAS, G. K.; TRIARIDIS, S.; KORDALI, P.; PSILLAS, G. \& BRAND-SABERI, B. Bilateral supernumerary sternocleidomastoid heads with critical narrowing of the minor and major supraclavicular fossae: clinical and surgical implications. Int. J. Morphol., 30(3):927-933, 2012.

la medial con su patrón típico, mientras que el lateral fue supernumeraria. La porción cleidomastoídea del músculo esternocleidomastoideo izquierdo se fusionó con el segmento esternocleidomastoideo doble. Un músculo acintado similar procedentes del tercio medio de la clavícula e inserción en el proceso transverso de la vértebra C3 fue observado. Éste se conoce como el músculo cleidocervical. En el lado derecho del cuello, el triángulo cervical posterior fue disminuido, la fosa supraclavicular menor fue considerablemente estrecha, mientras que en el lado izquierdo, se disminuyó además a un acortamiento bilateral del espacio fosa supraclavicular importante reducir al mínimo necesario para el acceso quirúrgico potencial. Estos hallazgos tienen una importancia destacada para los anestesistas en el posicionamiento de aguja guiada por ecografía en el bloqueo del plexo braquial, así como en la cateterización de la vena subclavia o yugular externa, y en las intervenciones quirúrgicas que afecta las estructuras situadas debajo del músculo esternocleidomastoideo.

PALABRAS CLAVE: Cleidocervical; cleido-occipital; esternocleidomastoideo; Esternomastoideo; fosa supraclavicular; ultrasonido; variante.

\section{REFERENCES}

Aiello, L. \& Dean, C. An introduction to human evolutionary anatomy. London, Academic Press, 1990. pp.210-31.

Asal, K.; Koybasioglu, A.; Inal, E.; Ural, A.; Uslu, S. S.; Ceylan, A. \& Ileri, F. Sternocleidomastoid muscle flap reconstruction during parotidectomy to prevent Frey's syndrome and facial contour deformity. Ear Nose Throat J., 84(3):173-6, 2005.

Asouhidou, I.; Natsis, K.; Asteri, T.; Sountoulides, P.; Vlasis, K. \& Tsikaras, P. Anatomical variation of left internal jugular vein: clinical significance for an anaesthesiologist. Eur. J. Anaesthesiol., 25(4):314-8, 2008.

Bayne, S. R.; Lehman, J. A. \& Crow, J. P. Lung herniation into the neck associated with congenital absence of the sternocleidomastoid muscle. J. Pediatr. Surg., 32(12):1754-6, 1997.

Bergman, R. A.; Thompson, S. A.; Afifi, A. K. \& Saadeh, F. A. Compendium of human anatomic variation. Rio de Janeiro, Urban \& Schwarzenbeg, 1988. p.607.

Conley, J. \& Gullane, P. J. The sternocleidomastoid muscle flap. Head Neck Surg., 2(4):308-11, 1980.

Coskun, N.; Yildirim, F. B. \& Ozkan O. Multiple muscular variations in the neck region--case study. Folia Morphol. (Warsz), 61(4):317-9, 2002.

Fasel, J.; Gailloud, P. \& Terrier, F. Three-dimensional reconstruction of a levator claviculae muscle. Surg. Radiol. Anat., 16(3):3035, 1994.
Feigl, G. C. \& Pixner, T. The cleidoatlanticus muscle: a potential pitfall for the practice of ultrasound guided interscalene brachial plexus block. Surg. Radiol. Anat., 33(9):823-5, 2011.

Grüber, W. Ein Musculus cleido-cervicalis s. trachelo-clavicularis imus. Arch. Anat. Physiol. Wissen Med., 757-8, 1876.

Haroon, S. \& Beverley, D. Congenital absence of the left sternomastoid muscle. Arch. Dis. Child. Fetal Neonatal Ed., 90(2):F102, 2005.

Hasan, T. Variations of the sternocleidomastoid muscle: a literature review. The Internet Journal of Human Anatomy,1(1), 2011. Available in: http://www.ispub.com/journal/the-internetjournal-of-human-anatomy/volume-1-number-1/variations-ofthe-sternocleidomastoid-muscle-a-literature-review.html

Klaastad, O.; Sauter, A. R. \& Dodgson, M. S. Brachial plexus block with or without ultrasound guidance. Curr. Opin. Anaesthesiol., 22(5):655-60, 2009.

Koshy, S.; Rabi, S. \& Indrasingh, I. Supernumerary cleidocervicalis (levator claviculae) muscle: Case report of its rare incidence with clinical and embryological significance. Eur. J. Anat., 9:103-6, 2005.

Kwak, H. H.; Kim, H. J.; Youn, K. H.; Park, H. D. \& Chung, I. H. An anatomic variation of the trapezius muscle in a Korean: the cleido-occipitalis cervicalis. Yonsei Med. J., 44(6):1098100, 2003.

Last, R. J. Anatomy. Regional and applied. Edinburgh, Churchill Livingstone, 1978.

Le Double, A. F. Traite des variations du systeme musculaire de l'homme et de leur signification au point de vue de l'anthropologie zoologique. Paris, Schleicher Freres editeurs, 1897.

Leon, X.; Maranillo, E.; Quer, M. \& Sanudo, J. R. Case report: cleidocervical or levator claviculae muscle. A new embryological explanation as to its origin. J. Anat., 187(Pt 2):503-4, 1995.

Loukas, M.; Sullivan, A.; Tubbs, R. S. \& Shoja, M. M. Levator claviculae: a case report and review of the literature. Folia Morphol. (Warsz), 67(4):307-10, 2008.

Mori, M. Statistics on the Musculature of the Japanese. Okajimas Folia Anat. Jpn., 40:195-300, 1964.

Natsis, K.; Asouchidou, I.; Vasileiou, M.; Papathanasiou, E.; Noussios, G. \& Paraskevas, G. A rare case of bilateral supernumerary heads of sternocleidomastoid muscle and its clinical impact. Folia Morphol. (Warsz), 68(1):52-4, 2009.

Nayak, S. R.; Krishnamurthy, A.; Sj, M. K.; Pai, M. M.; Prabhu, L. V. \& Jetti, R. A rare case of bilateral sternocleidomastoid muscle variation. Morphologie, 90(291):203-4, 2006. 
RAIKOS, A.; PARASKEVAS, G. K.; TRIARIDIS, S.; KORDALI, P.; PSILLAS, G. \& BRAND-SABERI, B. Bilateral supernumerary sternocleidomastoid heads with critical narrowing of the minor and major supraclavicular fossae: clinical and surgical implications. Int. J. Morphol., 30(3):927-933, 2012.

Parsons, F.G. The muscles of mammals with special relations to human mycology. J. Anat., 32:428-50, 1898.

Rahman, H. A. \& Yamadori, T. An anomalous cleido-occipitalis muscle. Acta Anat. (Basel), 150(2):156-8, 1994.

Ramesh, R. T.; Vishnumaya, G.; Prakashchandra, S. K. \& Suresh, R. Variation in the origin of sternocleidomastoid muscle. A case report. Int. J. Morphol., 25(3):621-3, 2007.

Rodríguez-Vázquez, J. F.; Merida-Velasco, J. R.; Verdugo-Lopez, S.; de la Cuadra-Blanco, C. \& Sanz-Casado, J.V. Anatomical relationships of the cleidoatlanticus muscle. Interpretation about its origin. Anat. Sci. Int., 84(1-2):47-52, 2009.

Rubinstein, D.; Escott, E. J. \& Hendrick, L. L. The prevalence and CT appearance of the levator claviculae muscle: a normal variant not to be mistaken for an abnormality. AJNR Am. J. Neuroradiol., 20(4):583-6, 1999.

Rudisuli, T. Demonstration of a musculus levator claviculae. Surg. Radiol. Anat., 17(1):85-7, 1995.

Ruiz Santiago, F.; Lopez Milena, G.; Chamorro Santos, C. \& Tristan Fernandez, J. M. Levator claviculae muscle presenting as a hard clavicular mass: imaging study. Eur. Radiol., 11(12):2561$3,2001$.

Sarikcioglu, L.; Donmez, B. O. \& Ozkan, O. Cleidooccipital muscle: an anomalous muscle in the neck region. Folia Morphol. (Warsz)., 60(4):347-9, 2001.

Tanaka, N.; Yamaguchi, A.; Ogi, K. \& Kohama, G. Sternocleidomastoid myocutaneous flap for intraoral reconstruction after resection of oral squamous cell carcinoma. J. Oral Maxillofac. Surg., 61(10):1179-83, 2003.

Tavill, M. A. \& Wetmore, R. F. A case of familial sternocleidomastoid tumor of infancy. Int. J. Pediatr. Otorhinolaryngol., 38(2):163-8, 1996.

Theis, S.; Patel, K.; Valasek, P.; Otto, A.; Pu, Q.; Harel, I.; Tzahor, E.; Tajbakhsh, S.; Christ, B. \& Huang, R. The occipital lateral plate mesoderm is a novel source for vertebrate neck musculature. Development, 137(17):2961-71, 2010.

Tomo, S.; Toh, H.; Hirakawa, T.; Tomo, I. \& Kobayashi, S. Case report: the cleidocervical muscle with speculation as to its origin. J. Anat., 184(Pt 1):165-9, 1994.

Vajramani, A.; Witham, F. M. \& Richards, R. H. Congenital unilateral absence of sternocleidomastoid and trapezius muscles: a case report and literature review. J. Pediatr. Orthop. B, 19(5):462-4, 2010.

Van Daele, D. J.; Finnegan, E. M.; Rodnitzky, R. L.; Zhen, W.; McCulloch, T. M. \& Hoffman, H. T. Head and neck muscle spasm after radiotherapy: management with botulinum toxin
A injection. Arch. Otolaryngol. Head Neck Surg., 128(8):9569, 2002.

Wood, J. On a group of varieties of the muscles of the human neck, shoulder, and chest, with their transitional forms and homologies in the mammalia. Proc. R. Soc. Lond., 160:1-3, 1869.

\section{Correspondence to:}

Athanasios Raikos, MD, Ph.D.

Assistant Professor of Anatomy

Department of Anatomy

Faculty of Health Sciences \& Medicine

Bond University

Gold Coast, QLD 4229

AUSTRALIA

Tel.: +61 755954411

Email: a.raikos@yahoo.com

Received: 27-04-2012

Accepted: 13-06-2012 